\title{
Understanding Magma Rise and Storage Using Major Elemental Diffusion in Olivine; Pupuke Maar, Auckland Field, New Zealand
}

\author{
MADISON ANAE ${ }^{1}$, VICTORIA CASSADY ${ }^{1}$, INGRID \\ UKSTINS $^{1}$, MARCO BRENNA ${ }^{2}$, SHANE CRONIN ${ }^{3}$, IAN \\ $\mathrm{SMITH}^{3}$
}

${ }^{1}$ EES Department, Univ. of Iowa, Iowa, USA

(madison-anae@uiowa.edu)

${ }^{2}$ Geology Department, University of Otago, Dunedin, New Zealand

${ }^{3}$ School of the Environment, University of Auckland, Auckland, New Zealand

The Auckland Volcanic Field (AVF) is spatially and temporally unpredictable, which is typical of monogenetic basaltic fields. It is one of the youngest small-scale volcanic systems on Earth with $>50$ eruptions ranging in age from ca. 300,000 to as recent as ca. 500 years old. Auckland City sits on top of this volcanic field with a population of 1.5 million, and a future eruption could impact up to 300,000 people. Ascent rates for mantle-derived magmas, from ca. 27 to 80 $\mathrm{km}$ depth, have been quantified to be on the order of 0.01 $0.03 \mathrm{~ms}^{-1}$ over an average of $37+/-6$ (2 sigma) days, but the complexity of magmatic storage systems are relatively unconstrained. Rare olivine mantle xenocrysts from the Pupuke Maar, Auckland Volcanic Field, show diffusion profiles indicating complex, multi-stage storage with residence times between 1 month to about 1 year.

In order to statistically quantify magma storage rates within the AVF, we selected >1000 mantle olivine xenocrysts from Pupuke for investigation. Each crystal was analyzed by electron microprobe to generate a backscatter electron greyscale image of the rim with compositional gradation, and 3 spots were analyzed on the margin and towards the core of each olivine for major and minor element composition. ImageJ was used to generate a diffusion profile and EMP spots were linked to the greyscale image to generate quantitative compositional information for all olivines. About $67 \%$ of analyzed olivines have short diffusion gradients of up to $70 \mu \mathrm{m}$ microns indicating elemental diffusion profiles that reflect residence times in the host magma from days to up to 1 month. About $6 \%$ of xenocrysts show step-change diffusion profiles which extend up to $200 \mu \mathrm{m}$ microns into the crystal, indicating magma mixing and multi-stage storage over protracted periods of a year or longer. EMP analyses of $\mathrm{P}$ indicated little to no overgrowth, implying zoning is due solely to elemental diffusion. The complexity of magma residence times and rapid rise rates have implications for hazard predictions for future Auckland Volcanic Field eruptions. 